\title{
The effects of congenital deafness on auditory nerve synapses and globular bushy cells in cats
}

\author{
Elizabeth E. Redd, Tan Pongstaporn, David K. Ryugo * \\ Center for Hearing Sciences, Johns Hopkins University School of Medicine, Traylor Research Building, 5th Floor, 720 Rutland Avenue, Baltimore, \\ MD 21205, USA
}

Received 14 August 1999; received in revised form 3 December 1999; accepted 4 December 1999

\begin{abstract}
It is well known that auditory deprivation affects the structure and function of the central nervous system. Congenital deafness represents one form of deprivation, and in the adult white cat, it has been shown to have a clear effect upon the synaptic interface between endbulbs of Held and spherical bushy cells. It is not known, however, whether all primary synapses are affected and/or whether they are affected in the same way and to the same extent. Thus, we studied a second neuronal circuit in the deaf white cat involving modified (small) endbulbs and globular bushy cells. Compared to normal hearing cats, modified endbulbs of congenitally deaf cats were $52.2 \%$ smaller but unchanged in structural complexity. There was also a striking loss of extracellular space between ending and cell body. The somata of postsynaptic globular bushy cells were $13.4 \%$ smaller and had enlarged postsynaptic densities. These data reveal that axosomatic synapses demonstrate abnormal structure as a consequence of deafness and that the extent of the abnormalities can vary with respect to the circuits involved. The implication of these observations is that synaptic anomalies would introduce differential delays within separate circuits, thereby desynchronizing neural activity from sound stimuli. This loss of synchronization could in turn disrupt temporal processing and compromise a host of related functions, including language comprehension. (C) 2000 Elsevier Science B.V. All rights reserved.
\end{abstract}

Key words: Endbulb; Extracellular cisterna; Hearing; Postsynaptic density

\section{Introduction}

The study of the influences of sound on the development and function of the central auditory system has clinical relevance because of observations that young children are better candidates for a cochlear implant compared to adults (Quittner and Steck, 1991; Fryauf-Bertschy et al., 1992; Waltzman et al., 1994; Gantz et al., 1994; Tyler and Summerfield, 1996). The ability to comprehend speech with a cochlear implant requires that the central auditory pathways encode, process, and organize the patterns of electrical stimulation into an auditory percept. The congenitally deaf white cat (DWC) exhibits cochleosaccular degeneration,

\footnotetext{
* Corresponding author. Tel.: +1 (410) 955-4543; Fax: +1 (410) 614-4748; E-mail: dryugo@bme.jhu.edu
}

which is a condition that mimics the Scheibe deformity in humans (Bosher and Hallpike, 1965; Deol, 1970; Suga and Hattler, 1970; Bergsma and Brown, 1971; Brighton et al., 1991). Thus, this animal may be used to model how congenital deafness affects the development and function of the central auditory system, especially in humans.

The Scheibe deformity features early onset, cochleosaccular degeneration and severe sensorineural hearing impairment (Scheibe, 1892). This defect is commonly associated with both syndromic and non-syndromic forms of deafness (Waardenburg, 1951; Deol, 1970; Nadol and Burgess, 1982; Brighton et al., 1991). The Scheibe deformity is also associated with measurable degenerative effects in the human auditory pathway (Moore et al., 1994).

In the DWC, the defect is transmitted in an autosomal dominant pattern with incomplete penetrance, and is identified by pigmentation abnormalities (white coat, 
heterochromic irides) and cochleosaccular degeneration (Rawitz, 1896; Wolff, 1942; Bosher and Hallpike, 1965; Bergsma and Brown, 1971). There are also atrophic structural changes in neurons of the central auditory pathway, which include the cochlear nucleus (West and Harrison, 1973; Larsen and Kirchhoff, 1992; Saada et al., 1996) and superior olivary complex (Schwartz and Higa, 1982). The cochleosaccular pathology of the DWC ranges from modest hair cell loss to complete collapse of the organ of Corti with variable degeneration of spiral ganglion cells and different degrees of hearing loss (Bosher and Hallpike, 1965; Mair, 1973; Pujol et al., 1977; Rebillard et al., 1981; Ryugo et al., 1998). Thus, this animal provides a rich and complex model of naturally occurring congenital deafness.

A recent study of deaf white kittens reported functional plasticity in the auditory cortex after cochlear implantation (Klinke et al., 1999). These researchers observed that kittens with cochlear implants could not only respond to environmental sounds but also exhibited cortical potentials suggestive of cognitive processing. Clearly, studies of the DWC may yield insights into why stimulus coding in some human implant recipients fails to provide adequate speech perception. It is in this context that we have been studying the primary synapses of the congenitally deaf cat.

We have demonstrated that one key synaptic interface between auditory nerve fibers and cochlear nucleus neurons exhibits abnormal structure in congenitally DWCs (Ryugo et al., 1997, 1998). The endbulb of Held is a large, axosomatic ending that arises from myelinated auditory nerve fibers and makes synaptic contact with spherical bushy cells in the anteroventral cochlear nucleus (AVCN). This specific ending is one of the largest synapses in the central nervous system (Lenn and Reese, 1966), and it initiates a circuit involved in the processing of interaural time differences (Irvine, 1986; Yin and Chan, 1988; Irvine, 1992). Compared to normal hearing cats, the synapses of the DWCs at this station exhibited a distinct reduction in synaptic vesicles and a hypertrophy of the postsynaptic density (PSD) (Ryugo et al., 1997, 1998). Our question was whether this alteration was unique to the endbulbs of Held or whether this type of change occurred for other primary axosomatic synapses in the AVCN. For this study, we report on the synaptic changes involving the modified endbulbs and globular bushy cells in the AVCN of congenitally DWCs.

\section{Materials and methods}

\subsection{Animal subjects}

Three male cats with white coats, green eyes and a family history of deafness represented the congenitally deaf population. One was 6 months old, one 9 months old and one 6.5 years old. Six pigmented cats with normal hearing, ranging in age from 6 months to 5.75 years, were used for comparison. Each had clean external and middle ears with no signs of infection to otoscopic exam. All animal procedures were approved by the Johns Hopkins University Animal Care and Use Committee, and were in strict accordance with the guidelines established by the NIH and with the principles of the Declaration of Helsinki.

\subsection{Auditory brainstem responses}

Each cat had its hearing tested prior to the auditory nerve injection. Behaviorally, the white cats did not respond to any auditory stimuli. During the week prior to the auditory nerve injection, cats were sedated with $0.9 \mathrm{cc}$ intramuscular ketamine hydrochloride $(100 \mathrm{mg} / \mathrm{ml})$, and $0.1 \mathrm{cc}$ intramuscular acepromazine $(20 \mathrm{mg} / \mathrm{ml})$, placed in a sound-proof chamber, sterile needle electrodes were inserted, one behind each ear, one at the vertex, and the ground wire into the nasal dorsum skin. Standard auditory brainstem evoked responses (ABRs) were collected and averaged from 1000 clicks (Tucker Davis Technologies, Inc.). Clicks were generated by passing a $100 \mu$ s pulse into the attenuators, with a maximum output at the headphones of $99 \mathrm{~dB}$ peak SPL (Burkard, 1984). ABR click recordings were made between the vertex electrode and the ipsilateral ear, indicating that the white cats had significant bilateral hearing loss (at least $90 \mathrm{~dB}$ SPL bilaterally) and that the pigmented cats had normal hearing thresholds (5-10 dB SPL).

\subsection{Animal preparation}

Cats were anesthetized with intramuscular injections of xylazine hydrochloride $(0.25 \mathrm{cc})$ and ketamine hydrochloride $(0.75 \mathrm{cc})$. Intramuscular atropine $(0.25 \mathrm{cc})$ was administered to reduce secretions. Thereafter, supplemental anesthesia with intraperitoneal injections ( $0.1 \mathrm{cc}$ per $\mathrm{kg}$ body weight) of diallyl barbituric acid $(100 \mathrm{mg} / \mathrm{ml})$ in urethane solution $(400 \mathrm{mg} / \mathrm{ml})$ was administered to maintain areflexia. Body temperature was monitored by a rectal thermometer, and maintained at approximately $39^{\circ} \mathrm{C}$ using a heating pad and our heated sound-attenuated chamber.

For each cat, the trachea was cannulated via tracheostomy, an intravenous line was placed in the cephalic vein for administration of balanced salt solutions, and the head placed in a stereotaxic device. The skin, muscle layers and aponeuroses were incised over the skull, and dissection was continued to each external meatus. The posterior cranial fossa was opened with rongeurs, the 
cerebellum was exposed, the dura reflected, and the cerebellum was retracted one side at a time for exposure of the auditory nerve in its course from internal auditory meatus to cochlear nucleus. Under direct visual control, micropipettes filled with horseradish peroxidase (HRP) were inserted into the auditory nerve.

\subsection{Extracellular injections and tissue preparation}

In all cats, a $30 \%$ solution of HRP in 0.05 Tris buffer $(\mathrm{pH}$ 7.3) was injected into each auditory nerve by passing $5 \mu \mathrm{A}$ of positive current ( $50 \%$ duty cycle) through a micropipette (internal diameter $40 \mu \mathrm{m}$ ) for $5 \mathrm{~min}$. Between 20 and $24 \mathrm{~h}$ after HRP was injected, each cat was given a lethal dose of anesthesia, the heart surgically exposed, and heparin sulfate $(0.1 \mathrm{cc})$ was injected directly into the heart. Approximately $100 \mathrm{cc}$ of $0.1 \mathrm{M}$ phosphate-buffered saline ( $\mathrm{pH} 7.4$ ) containing 1\% sodium nitrite (for vasodilation) was then perfused intracardially, immediately followed by approximately 1.51 of fixative containing $2 \%$ paraformaldehyde and $2 \%$ glutaraldehyde in $0.1 \mathrm{M}$ phosphate buffer.

Following perfusion, each brain was postfixed overnight in fresh fixative at $5^{\circ} \mathrm{C}$. The cochlear nuclei were dissected and embedded in a gelatin-albumin mixture hardened with glutaraldehyde. Sections were cut at a thickness of $50 \mu \mathrm{m}$ on a Vibratome oriented parallel to the lateral surface of the nuclei, collected in serial order in $0.1 \mathrm{M}$ phosphate buffer, washed in the same buffer several times, and incubated for $60 \mathrm{~min}$ in phosphate-buffered $0.05 \%$ 3,3'-diaminobenzidine (Sigma, grade II Tetra $\mathrm{HCl}$ ) activated with hydrogen peroxide. Sections were then washed multiple times with $0.1 \mathrm{M}$ phosphate buffer and processed for electron microscopy as follows.

The tissue was placed in $1 \% \mathrm{OsO}_{4}$ for $15 \mathrm{~min}$, rinsed $5 \times 5 \mathrm{~min}$ in $0.1 \mathrm{M}$ maleate buffer ( $\mathrm{pH} 5.0)$, and stained in $1 \%$ uranyl acetate in methanol overnight. The following morning, the sections were washed with $0.1 \mathrm{M}$ maleate buffer, dehydrated in increasing concentrations of ethanol, infiltrated with Epon, and embedded in fresh Epon between sheets of Aclar. Hardened sections were taped to labeled microscope slides for examination with a light microscope. Relevant structures were identified and dissected from individual sections and re-embedded in BEEM capsules for electron microscopic analysis. Ultrathin sections of approximately $75 \mathrm{~nm}$ thickness were collected on Formvar-coated grids, stained with $7 \%$ uranyl acetate, and viewed and photographed with a JEOL 100CX electron microscope. Because each ultrathin section represents a thin slice through each endbulb, only parts of the labeled endbulb can appear in any section and are referred to as 'ending profiles'.

\subsection{Data collection and analysis: light microscopy}

Modified endbulbs are distributed in the vicinity of the auditory nerve root, are distinctly smaller than endbulbs of Held of the rostral AVCN, and make contact with globular bushy cells (Lorente de Nó, 1981; Harrison and Irving, 1966; Rouiller et al., 1986). HRP-labeled modified endbulbs and globular bushy cells were first mapped using low magnification $(31.25 \times)$ and then drawn at high magnification $(100 \times$ oil immersion objective, NA 1.3 , total magnification $2500 \times$ ) with the aid of a light microscope and drawing tube. All modified endbulbs selected for analysis were located in the caudal AVCN around the auditory nerve root and were closely apposed to globular bushy cells. Globular bushy cells are identifiable by their large, pear-shaped cell bodies, uniformly staining cytoplasm with an absence of prominent Nissl bodies, and a pale, round, eccentrically placed nucleus that is also relatively small. Nisslstained cells were drawn at $2500 \times$ magnification.

Drawings of cell bodies and modified endbulbs were digitized using a flatbed scanner (Umax Astra 2400S) for purposes of silhouette area measurements and fractal analysis. Fractal geometry has provided a quantitative descriptor of the complexity of natural structures (Mandelbrot, 1982), and has been used to assess the complexity of endbulbs of Held (Ryugo et al., 1997). We applied the box counting technique (Fractal Dimension Calculator, v1.5), where a grid of squares having 12 different sizes $(s)$ is placed over the outline of the endbulb, and for each size, the number of squares $N(s)$ that contain any portion of the endbulb is counted (Fig. 1). The fractal dimension $D$ is given by the slope of the linear portion of the line when $\log [N(s)]$ is plotted against $\log (1 / s)$, derived from the relationship log $[N(s)]=D \log (1 / s)$. Because there is no preferred origin for the boxes with respect to the pixels in the image, multiple measures $N(s)$ are computed from nine different box origins, and the graphed value of $N(s)$ is the average from the different origins. Fractal values range between 1 and 2, and because the fractal index is represented on a logarithmic scale, each increase of 0.1 in the fractal dimension represents a doubling of structural complexity (Porter et al., 1991). Silhouette area measurements were performed using the software, NIH Image v1.61.

\subsection{Data collection and analysis: electron microscopy}

Twenty-three modified endbulbs, 11 from the adult DWCs and 12 from the normal hearing cats, were analyzed exclusively by electron microscopy. Ending profiles and PSDs were serially reconstructed from electron micrographs. Consecutive sections (15-25) were aligned using NIH Image v1.61, the resulting 'stack' rendered 


\section{Fractal Index Anaylsis Demonstration}

Modified endbulb

(simpler shape)
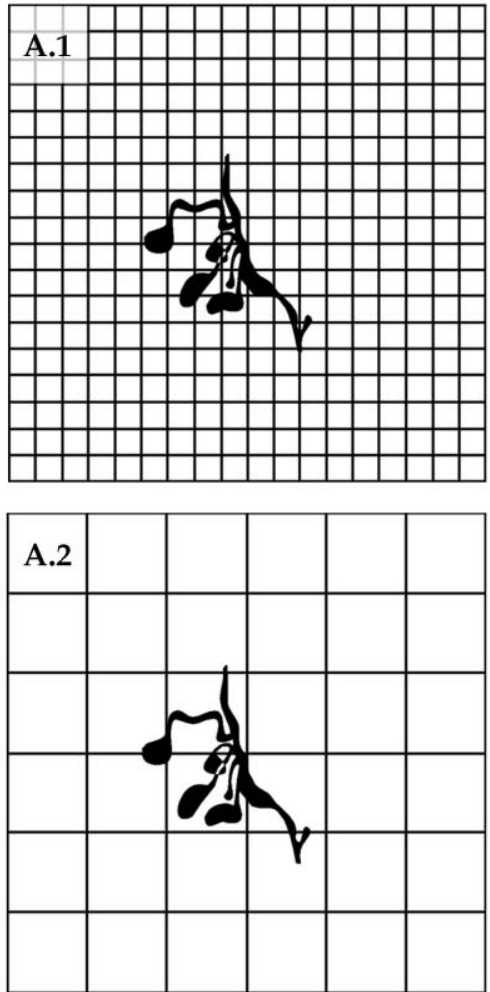

Endbulb of Held

(complex shape)
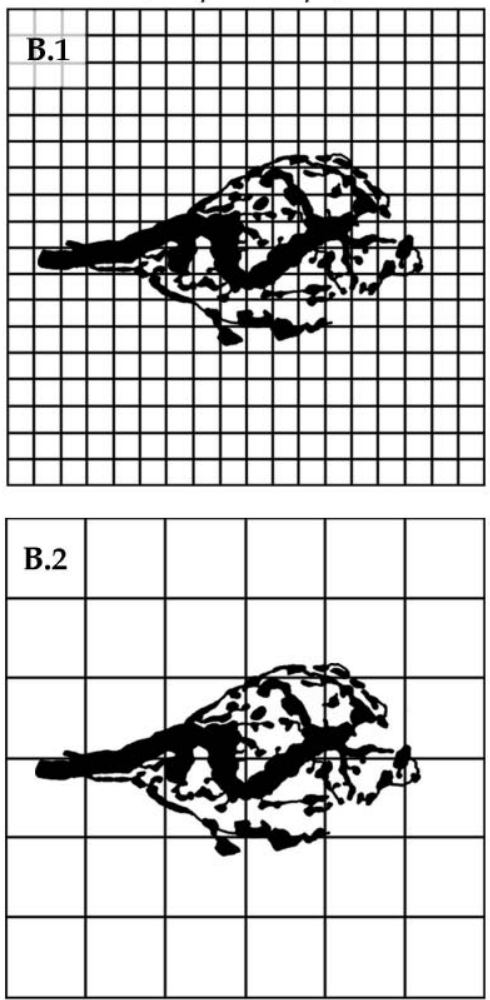

Fractal Indexes Graphed:
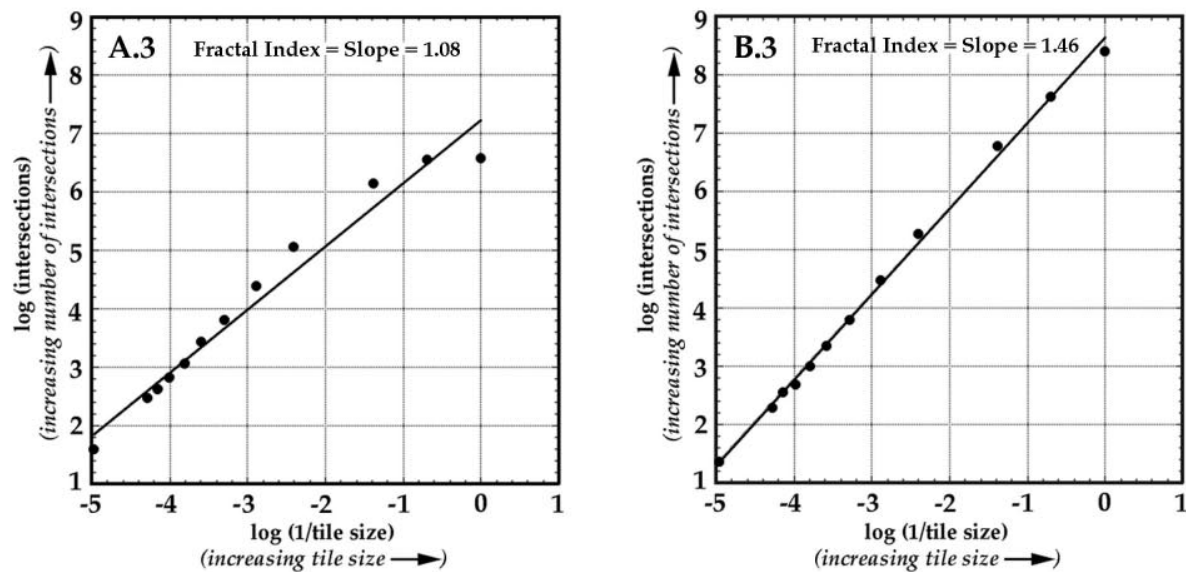

Fig. 1. Illustration of fractal index calculation for two structures of different complexity. Left column (A.1-A.3) demonstrates analysis of a modified endbulb from Fig. 2. Right column (B.1-B.3) demonstrates analysis of an endbulb of Held. A.1 and B.1 show the shapes overlaid on medium sized grids, and A.2 and B.2 use larger grids. The structures have more intersections with the smaller grids than with the larger grids. A.3 and B.3 plot the relationship between 12 grids of various sizes ( $x$-axis) and the corresponding number of intersections ( $y$-axis). A greater slope indicates a more complex shape.

into a three-dimensional image (Voxblast), and then rotated into optimal position and viewed. The reconstructed PSDs were best appreciated when viewed en face and analyzed as they resided on the somatic surface of the globular bushy cell. The area for each PSD contained within the reconstructed ending segment was determined.

The contact surface between the primary ending and postsynaptic cell was called the apposition area. It should be noted, however, that the presynaptic mem- 
brane was often invaginated or ruffled, creating an extracellular space. Thin glial processes were occasionally found within this space. The cell surface overlying this space was defined as 'non-apposition' area. One measure of PSD distribution was the ratio of PSD area to apposition area. This ratio was used to assess the amount of PSD change when comparing normal hearing and congenitally deaf cats.

Section thickness was estimated using standard interference reflection colors as the sections floated in the knife trough. The sections were silver in color, more gray than gold, and we estimate their thickness at 75 $\mathrm{nm}$. This value is consistent with our reconstructions, because 13 sections, when rotated $90^{\circ}$ and viewed en face, span slightly less than $1 \mu \mathrm{m}$ as determined by a calibration grid, and 14 sections slightly exceeded $1 \mu \mathrm{m}$. Means, standard deviations and $P$ values are provided where appropriate, and group comparisons were conducted using Student's $t$-test (two-tailed, unpaired) or Mann-Whitney $U$-test (Statview v5, SAS Institute, Inc.). Photographic negatives were digitized (Leafscan 45), the contrast and/or exposure adjusted (if necessary), simulating standard darkroom techniques (Adobe Photoshop), and the files printed in high resolution format (Fuji Pictrography 3000).

\section{Results}

\subsection{Light microscopy}

Globular bushy cells and their association with modified endbulbs were readily evident in both normal and congenitally deaf cats (Fig. 2). Labeled auditory nerve fibers entered the cochlear nucleus from its ventral aspect, ascended a variable distance into the nucleus depending on their site of cochlear innervation, and bifurcated into an ascending and descending branch. Collaterals of these branches near the bifurcation point and from the root branch traveled short distances before terminating in a small and relatively confined constellation of interlinked swellings. These distinctive endings associated with globular bushy cells in and around the region of bifurcations of auditory nerve fibers, and were called 'modified endbulbs'. Modified endbulbs received their name by virtue of their small size but resemblance to the large endbulbs of Held in the rostral AVCN (Harrison and Irving, 1966). The end of the collateral branch is marked by a swelling of variable size and shape, from which short filaments or branches emerge and terminate as a complex of swellings (Fig. 3). Under the light microscope, it was difficult to differentiate between modified endbulbs of normal and deaf cats. Consequently, modified endbulbs were drawn and subjected to quantitative analysis.

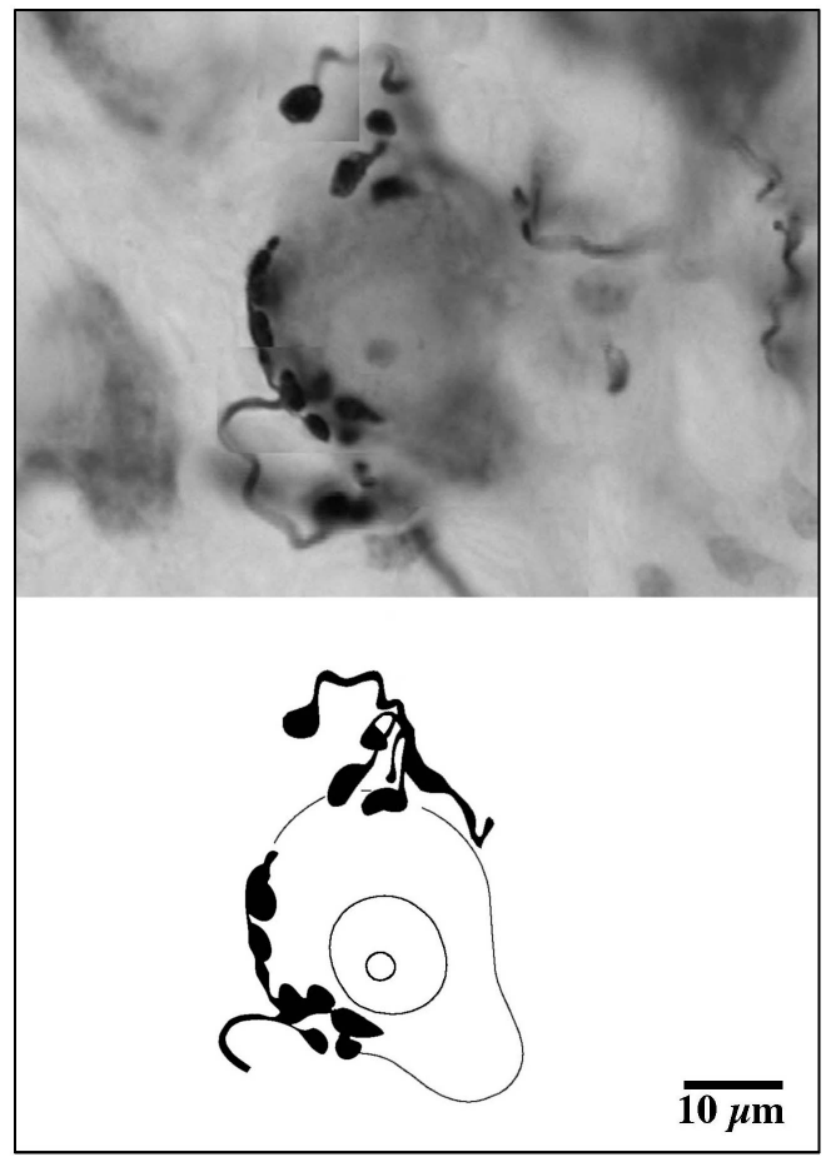

Fig. 2. Photomontage of globular bushy cell, contacted by two HRP-labeled, modified endbulbs in a normal hearing cat (upper panel). This combination of endings on second-order neurons is common in the region of the auditory nerve root in the ventral cochlear nucleus. Lower panel: drawing tube reconstruction of the same, HRP-labeled, modified endbulbs.

Fractal analysis and light microscopy silhouette area determinations were made for modified endbulbs and the resulting values were compared for normal hearing $(n=48)$ and congenitally deaf cats $(n=26)$. There was no difference in structural complexity between the two groups of cats as revealed by fractal analysis $(P=0.46)$. The average silhouette area of modified endbulbs, however, was significantly smaller (Student's $t$-test, twotailed, $P<0.001)$ for deaf cats $\left(31.28 \pm 15.3 \mu \mathrm{m}^{2}\right)$ compared to normal hearing cats $\left(65.40 \pm 46.7 \mu \mathrm{m}^{2}\right)$. Thus, congenital deafness reduced the size of modified endbulbs by $52.2 \%$ but had no detectable effect on structural complexity.

Measurements of cell body silhouette area revealed that there was a significant difference in somatic size between the two groups of cats. Globular bushy cells normally have among the largest cell bodies in the ventral cochlear nucleus, and these averaged $608.97 \pm 205.5$ $\mu \mathrm{m}^{2}(n=57)$ for the group of hearing cats, whereas the average size from the congenital deaf cats was 
$527.14 \pm 100.7 \quad \mu^{2} \quad(n=86)$. This size difference $(P<0.002)$ represented a $13.4 \%$ reduction.

\subsection{Electron microscopy}

In the electron microscope, globular bushy cells are also distinctive (Fig. 4). Their cytoplasm is characterized by many free ribosomes and ribosomal rosettes, and scant amounts of stacked arrays of rough endoplasmic reticulum. Golgi complexes are common, and the pale, round nucleus occupies a relatively small volume compared to that of the cell body. The nuclear envelope is smooth and there is an associated ring of free ribosomes. The plasma membrane of the cell body has an irregular contour, with shallow undulations and frequent spine-like appendages that protrude between synaptic terminals. The somatic surface is studded with endings, of which there are three principle types: those with large, round synaptic vesicles that are primary in origin, those with pleomorphic synaptic vesicles, and those with flattened synaptic vesicles. It should be stressed that globular bushy cells are readily distinguishable from multipolar (stellate) neurons that co-populate this region because multipolar neurons exhibit an angular somatic shape and prominent stacks of rough endoplasm (Tolbert and Morest, 1982a,b,c).

A number of modified endbulbs from separate auditory nerve fibers converge upon a single globular bushy cell (Lorente de Nó, 1981; Fekete et al., 1984; Ostapoff and Morest, 1991). This number has been estimated to be 17 (Spirou et al., 1990), representing 60\% of the terminal space along the somatic surface (Tolbert and Morest, 1982c). It is inferred that the dominant population of endings with clear, round synaptic vesicles are primary because they disappear following destruction of the cochlea (Tolbert and Morest, 1982c). Non-primary endings, identified by their contents of flattened or pleomorphic synaptic vesicles, also contact the bodies of globular bushy cells, but these cover less than $15 \%$ of the somatic surface. Although most of the endings on globular bushy cells were primary, we nevertheless had to establish criteria for recognizing modified endbulbs in the electron microscope that were unlabeled because the HRP reaction product obscured intracellular characteristics. We analyzed the ultrastructural characteristics of modified endbulbs that were labeled with HRP reaction product (Fig. 5, top panel), and noted that modified endbulbs were characterized by a rather homogeneous distribution of clear, round synaptic vesicles, frequent presynaptic membranous infoldings and intermembranous lacunae, and strikingly convex PSDs. The profile of a modified endbulb in a single section could have the same appearance as that of a simple bouton ending. However, by following each profile through a series of sections, the ending

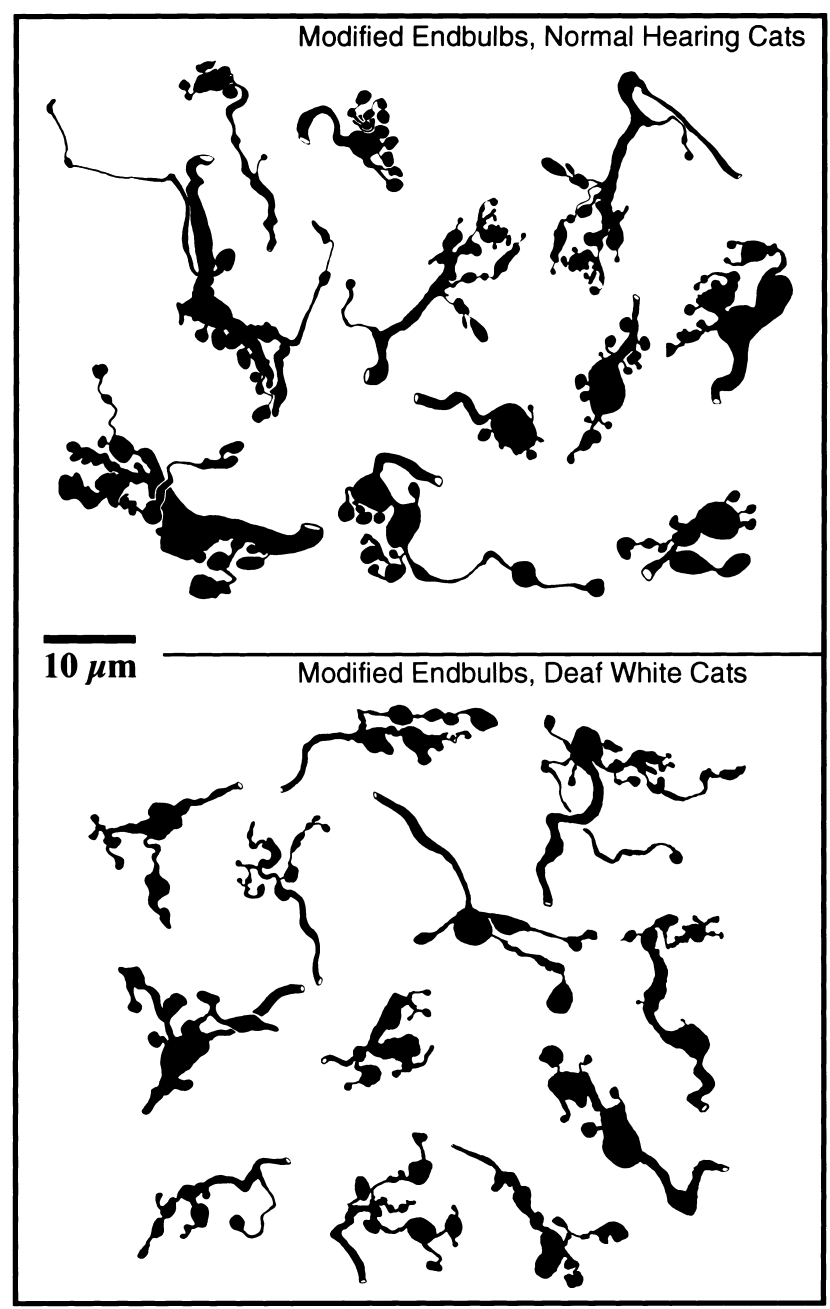

Fig. 3. Drawing tube reconstructions of modified endbulbs from normal hearing cats (upper panel) and congenitally DWCs (lower panel). Although modified endbulbs from the deaf cats are smaller in silhouette area, they are not less complex in structure as determined by fractal analysis.

could be traced back to a larger and more complicated profile typical for a modified endbulb, and occasionally traced back to its myelinated parent collateral. These features of labeled modified endbulbs matched with those of unlabeled endings contacting the same cell body (Fig. 5, bottom panel), were in agreement with those of a previous report (Tolbert and Morest, 1982c), and allowed us to infer the identity of unlabeled modified endbulbs with confidence.

The modified endbulbs of congenitally deaf cats exhibited two prominent structural differences when compared to those of normal hearing cats. First, there was a difference in the PSDs. In normal cats, the PSDs of globular bushy cells are punctate and tend to reside on distinct somatic convexities that indent the presynaptic membrane (Fig. 6, top panel). In other words, the PSDs were dome-shaped. By contrast, the PSDs of con- 


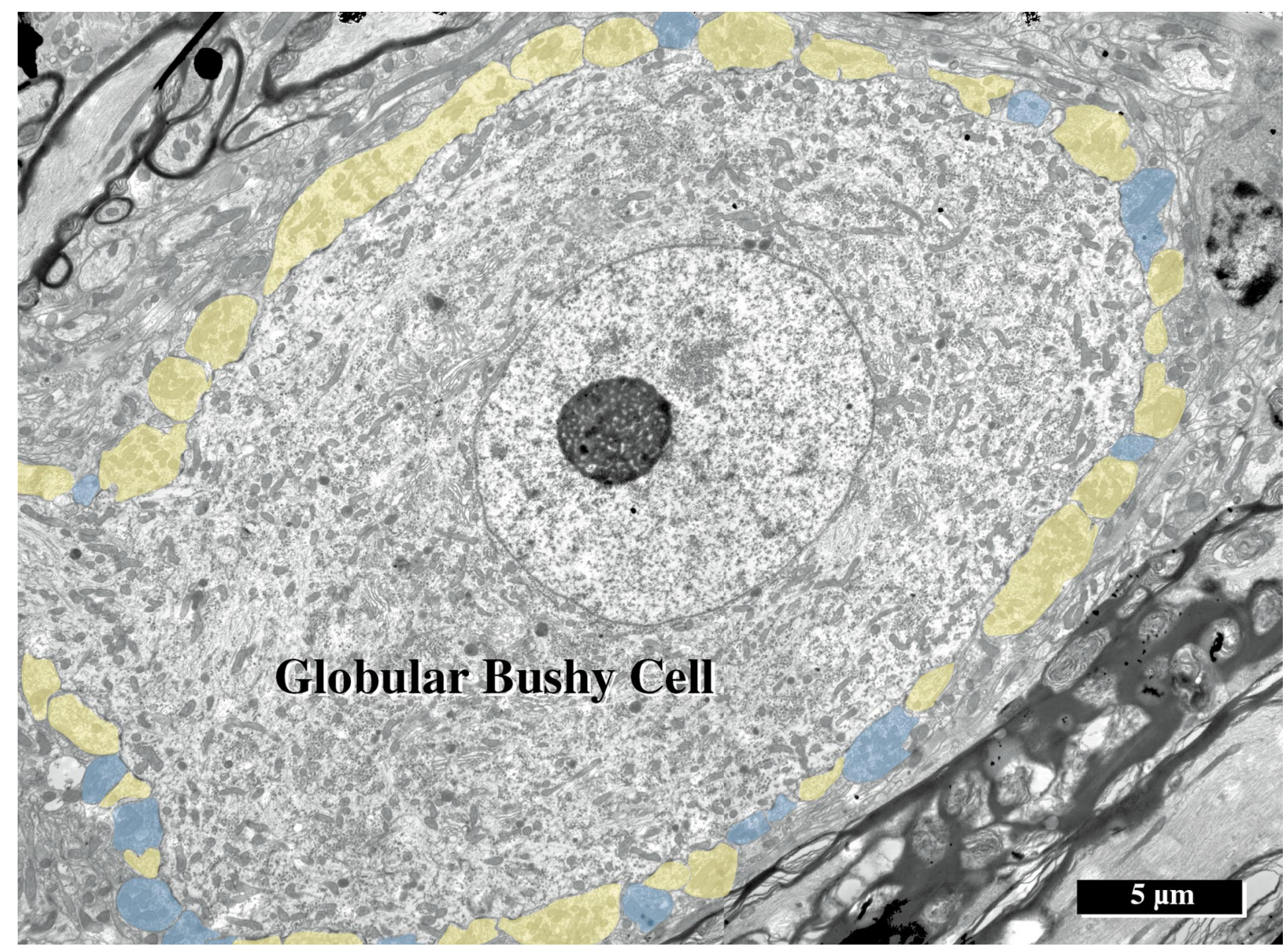

Fig. 4. Electronmicrograph of globular bushy cell. This class of neuron was identifiable in the electron microscope by the presence of its irregular somatic surface, an abundance of cytoplasmic ribosomes, and perinuclear Golgi. Primary (yellow) and non-primary (blue) terminals surround the somatic surface. The nucleus is pale and round with a smooth envelope. There is a relative lack of organized stacks of rough endoplasmic reticulum in the cytoplasm.

genitally deaf cats were larger but flattened (Fig. 6, bottom panel). Through serial section reconstructions and computer-assisted rotations, we measured the individual PSD surface area on the somata of globular bushy cells as viewed en face (Fig. 7). The impression gained by observing single sections was quantitatively verified by these measurements. The mean PSD area for hearing cats was $0.127 \pm 0.06 \mu \mathrm{m}^{2}$, whereas it was $0.242 \pm 0.15 \mu \mathrm{m}^{2}$ for congenitally deaf cats $(P<0.01$, Mann-Whitney $U$-test). There is a slight increase in synaptic vesicle density $(P<0.05$, Mann-Whitney $U$ test) in endings of congenitally deaf cats where the mean value is $75.26 \pm 22.7$ vesicles $/ \mu \mathrm{m}^{2}$, compared to that of normal hearing cats is $62.11 \pm 30.4$ vesicles $/ \mu \mathrm{m}^{2}$.

The other major difference concerned the extracellular spaces. These spaces are formed by a separation of the apposing pre- and postsynaptic membranes (Figs. 5 and 6, top panel), seemingly reflecting an invagination of the presynaptic membrane to varying degrees. Vir- tually all of these spaces vanished from modified endbulbs of the congenitally deaf cats (Fig. 6, bottom panel). We reconstructed the facing edges of these lacunae using the same methods as for the PSD analysis, and determined that the mean open area for normal hearing cats was $0.349 \pm 0.42 \mu \mathrm{m}^{2}$, compared to $0.01 \pm 0.03 \mu \mathrm{m}^{2}$ for congenitally deaf cats $(P<0.01$, Mann-Whitney $U$ test). All of these changes were consistent across the DWCs, revealing that synaptic changes were present by 6 months of age and that the abnormalities were not exacerbated in cats with longer periods of deafness.

\section{Discussion}

In this report, we describe the deafness-related changes that occur in the structure of one class of primary endings, the modified endbulbs, and the neurons upon which they terminate, the globular bushy cells 


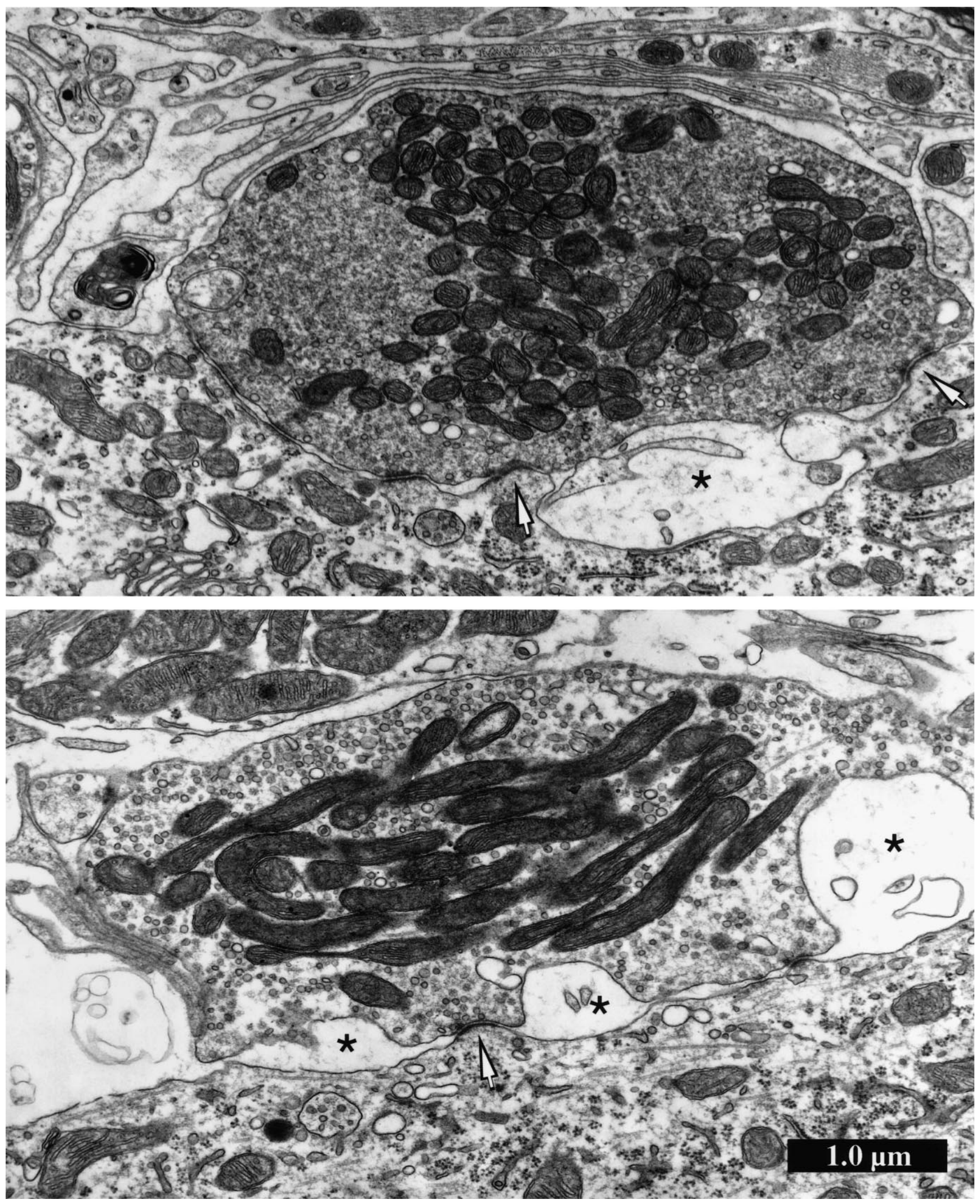

Fig. 5. Electronmicrographs of modified endbulbs from normal hearing cats. The presence of intracellular HRP reaction product facilitated the unambiguous identification of modified endbulbs (top panel), revealing a relatively uniform distribution of clear, round synaptic vesicles, extracellular cisternae $(*)$, and punctate, dome-shaped PSDs (arrows). These criteria permit us to identify and analyze unlabeled modified endbulbs (bottom panel). 

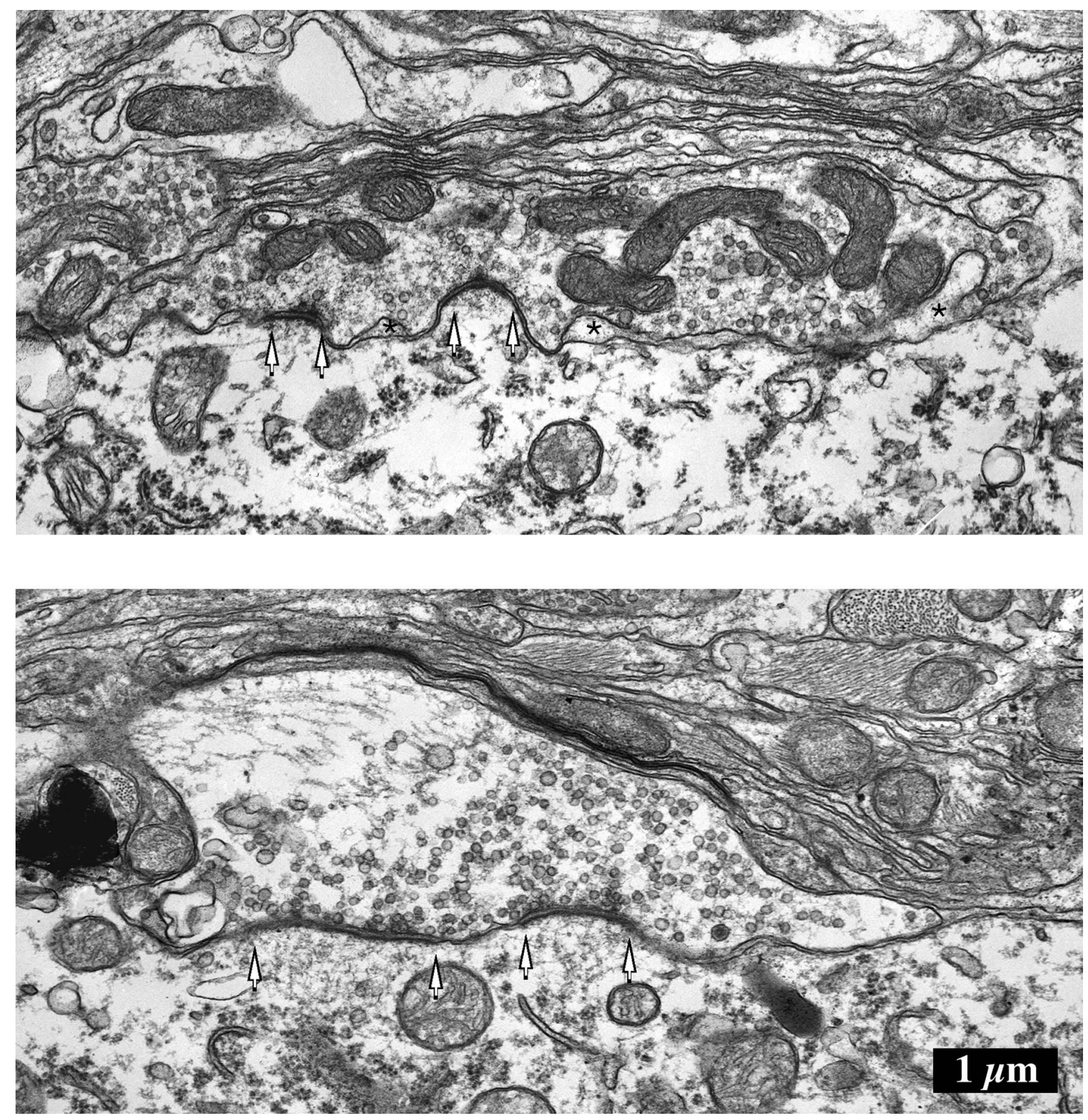

Fig. 6. Electronmicrographs of modified endbulbs from a normal hearing cat (top panel) and a congenitally DWC (bottom panel). A typical modified endbulb from the hearing cats displays its dome-shaped PSDs (arrows) and extracellular cisternae (*). In contrast, a representative modified endbulb from a congenitally DWC exhibits longer and flatter PSDs and an absence of extracellular cisternae.

(Fig. 8). There are a constellation of synaptic abnormalities that include reductions in the size of the primary endings and postsynaptic cell bodies, hypertrophy of PSDs, and conspicuous loss of extracellular space between endings and target neurons. These changes are consistent with congenital anomalies reported for another class of primary endings, the endbulbs of Held, and their target neurons, the spherical bushy cells (Ryugo et al., 1997, 1998). For this latter class of endings, the abnormalities included a reduction in endbulb size and branching complexity, a reduction in spherical bushy cell somatic size, a decrease in synaptic vesicle density, and a flattening and hypertrophy of PSDs (Fig. 9). Our data revealed that deafness did not affect pri- 
mary synapses in an identical way because globular bushy cells and modified endbulbs manifested their own distinct set of abnormalities. What was common across the two separate sets of neural circuits was that the severity of the abnormalities in cochlear nucleus neurons did not change markedly with age.

It is not surprising that different synaptic endings and different neuron populations might exhibit differential sensitivities to congenital deafness. After all, they differ along many biological variables including spike discharge levels, temporal response patterns, and thresholds to activation (Pfeiffer, 1966; Young et al., 1988; Blackburn and Sachs, 1989), composition of ion channels and transmitter receptors (Manis and Marx, 1991; Oertel, 1991; Rubio and Wenthold, 1997), dendritic morphology (Brawer et al., 1974; Hackney et al., 1990), sources of inputs (Spangler et al., 1987; Cant and Morest, 1978; Schofield and Cant, 1996), and output projections (Ryugo et al., 1981; Warr, 1982; Doucet and Ryugo, 1997). The non-uniform degree of deafness-induced abnormalities will most probably exert widespread yet unpredictable disruption of the system, and merits further discussion.

\subsection{Ending size and complexity}

Modified endbulbs are endings with branches, multiple en passant and terminal swellings, and many active zones. They are, however, much smaller than endbulbs of Held found in the rostral AVCN. Endbulbs of Held exhibit quantifiable structural differences with respect to spike discharge levels, where those from low activity auditory nerve fibers are more complex than those from high activity fibers (Ryugo and Sento, 1991). In contrast, modified endbulbs do not show this activityrelated effect (unpublished observations). Unlike modified endbulbs, endbulbs of Held show a reduction in branching complexity that is associated with congenital deafness (Ryugo et al., 1997, 1998). Both types of endings, however, exhibit shrinkage when spike activity is reduced. We do not know why deafness produces a differential effect on structural complexity, but it may reflect a kind of graded phenomenon where simple structures are less affected.

\subsection{PSDS}

Deafness does produce hypertrophy of PSDs in both spherical and globular bushy cells, suggesting an upregulation of transmitter receptors. This growth of the PSDs, where transmitter receptors are localized (Nusser et al., 1994), may be considered a compensatory response to reduced transmitter release. That is, in the face of diminished or absent spike activity, there may be a proliferation of receptors so that on those infre-
En face Views of Modified Enbulbs of Normal Hearing Cats
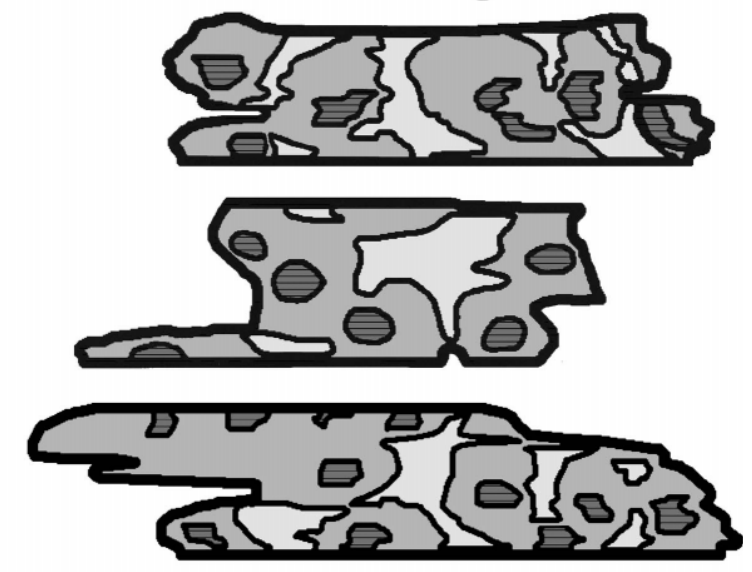

$1.0 \mu \mathrm{m}$

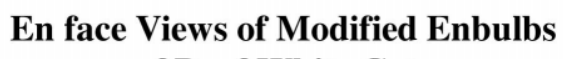

of Deaf White Cats
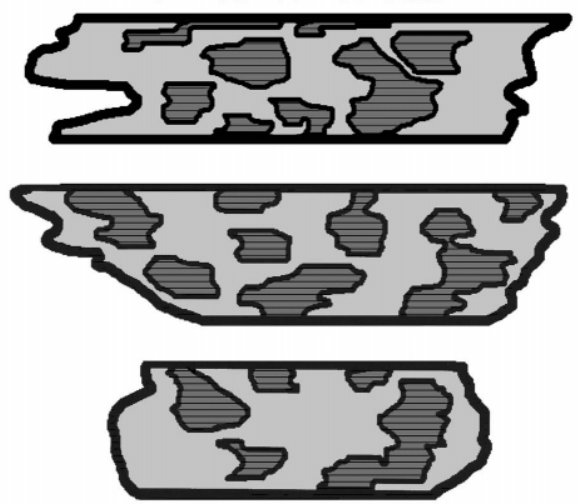

Fig. 7. En face views of the reconstructed somatic surface of globular bushy cells lying postsynaptic to the modified endbulbs. The PSDs from normal hearing cats (top) are relatively small (dark gray with horizontal lines) and are flanked by extracellular cisternae (light gray). Modified endbulbs from congenitally DWCs (bottom) reveal the hypertrophy of the PSDs (dark gray with horizontal lines) and a lack of extracellular cisternae. The horizontal lines in the PSDs indicate each ultrathin section involved in the reconstruction.

quent occasions when transmitter is released, the postsynaptic cell will have optimized its potential for responding. The other aspect of PSD change with deafness is a loss of curvature. PSD curvature is a signature feature of auditory nerve synapses, and it must impart some biological significance. Perhaps this membrane curvature controls protein conformation across the lipid bilayer and modulates receptor function. The flattening of PSDs might reflect a consequence of synapse inactivity where voltage changes and/or calcium influx is lost.

\subsection{Synaptic vesicles}

Synaptic vesicle density seems related to the efficacy 


\section{GLOBULAR BUSHY CELL}

NORMAL

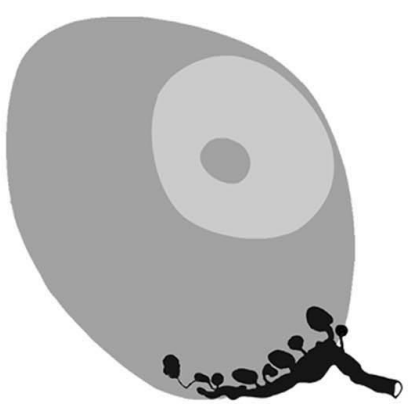

Modified Endbulb

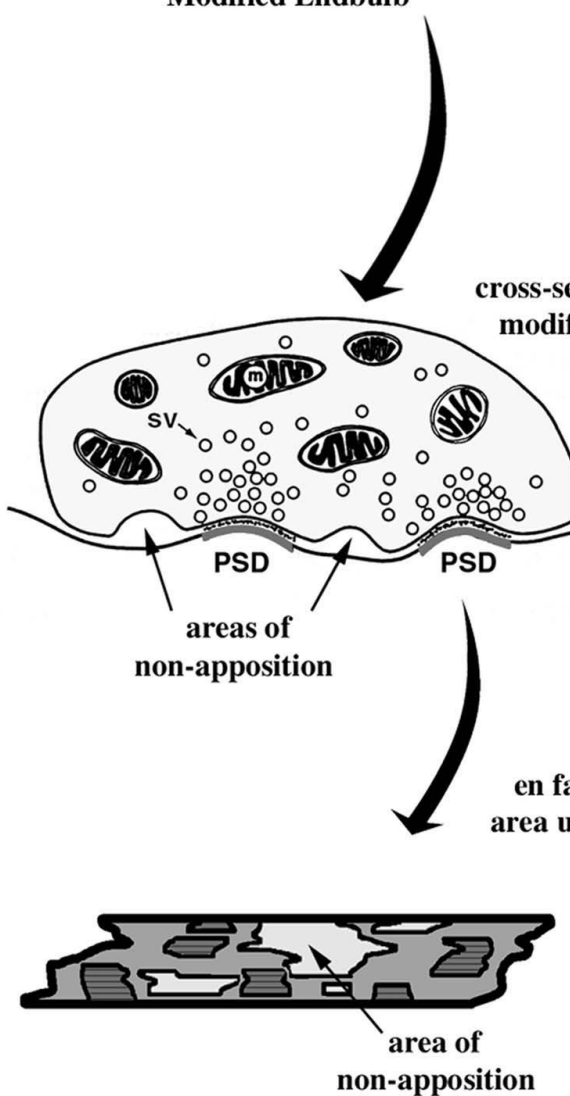

DEAF

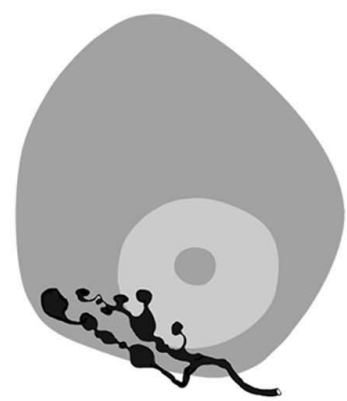

Modified Endbulb

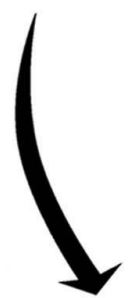

$10.0 \mu \mathrm{m}$ dbulb

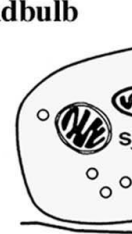

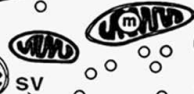

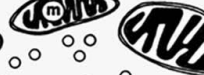

$0_{0} \circ$

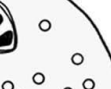

800 08900

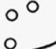

PSD

PSD

$0.25 \mu \mathrm{m}$

n face view of rea under ending
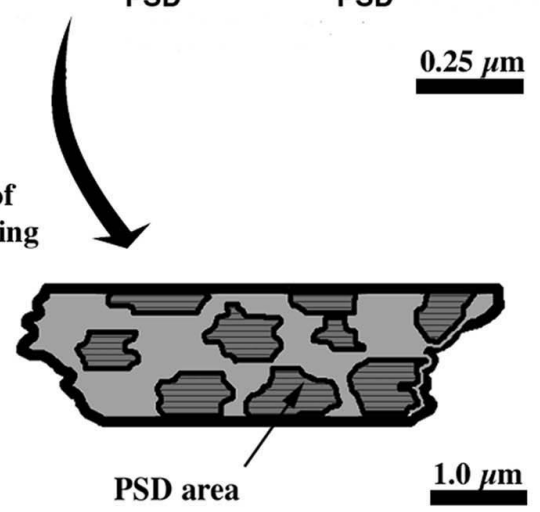

Fig. 8. Summary diagram of the changes observed for modified endbulbs and globular bushy cells. Compared to hearing cats, the deaf cats exhibit equally complex but smaller modified endbulbs, slightly shrunken globular bushy cells, hypertrophy and flattening of PSDs, and complete loss of extracellular cisternae. It is proposed that these structural alterations would impair processing involved in the analysis of binaural intensity differences.

of neurotransmission, and it is expected that vesicle density might change as a consequence of synaptic activity or inactivity. Modified endbulbs exhibit a slight deafness-related increase in synaptic vesicle density. This effect is in sharp contrast to a deafnessrelated loss of vesicles in endbulbs of Held. It may be, however, that the relative increase in synaptic vesicle density for modified endbulbs reflects a reduction in ending size with no change in absolute vesicle number. The mean profile area of modified endbulbs for normal hearing cats was $2.61 \pm 0.99 \mu \mathrm{m}^{2}$, whereas that for congenitally deaf cats was $2.11 \pm 1.1 \mu \mathrm{m}^{2}$, represent- 


\section{SPHERICAL BUSHY CELL}

NORMAL

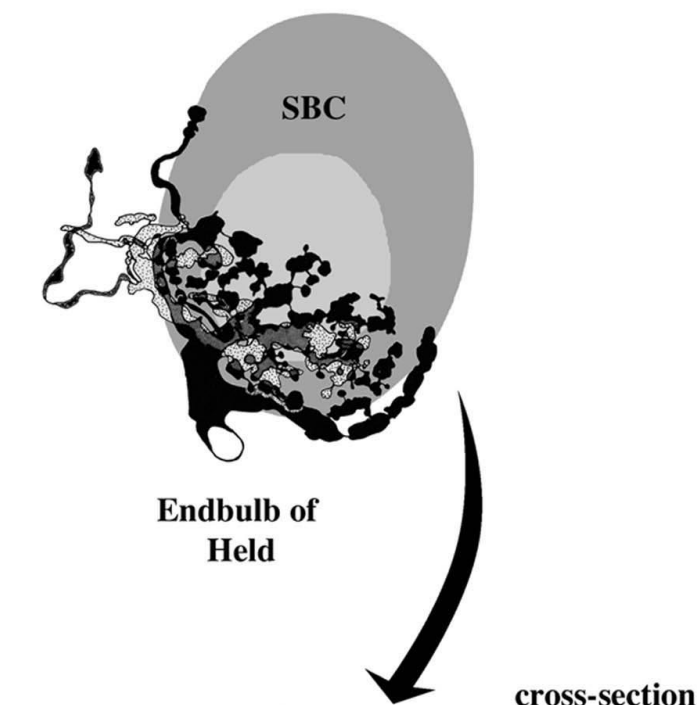

DEAF

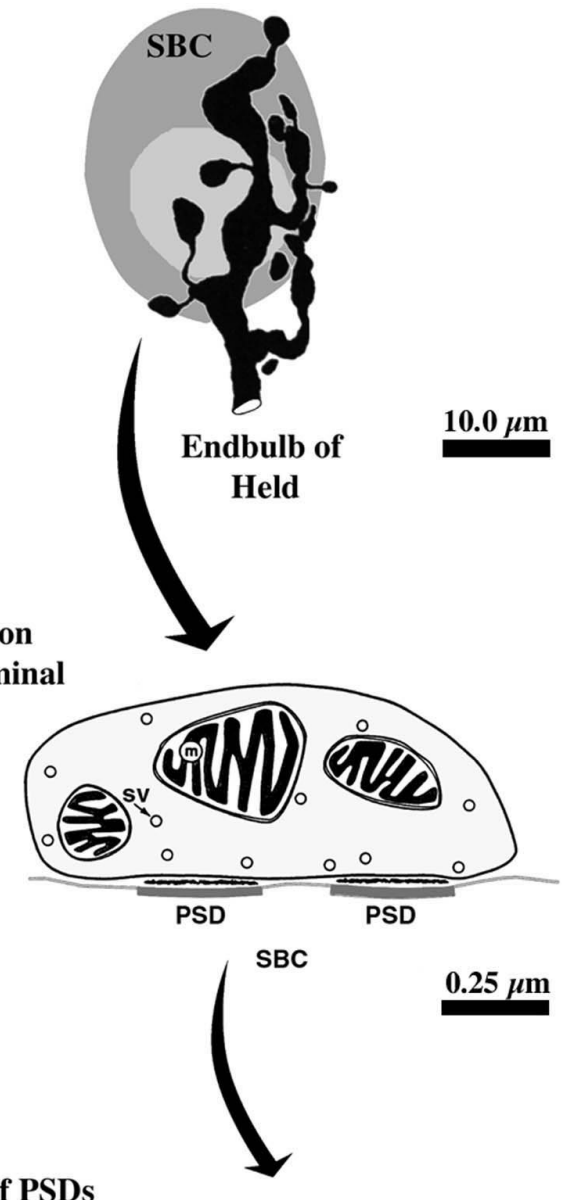

en face view of PSDs through terminal
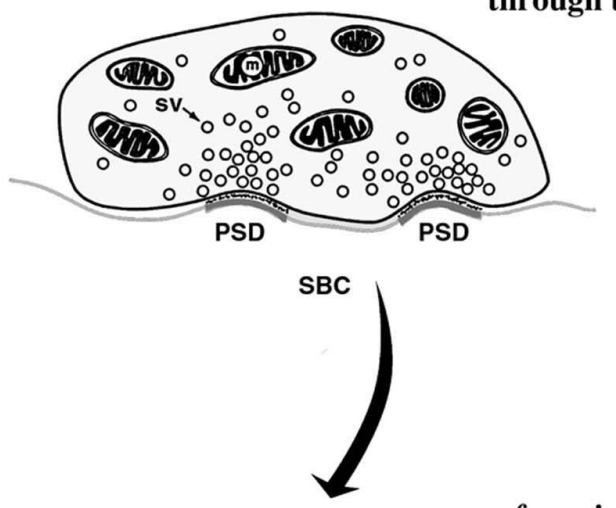
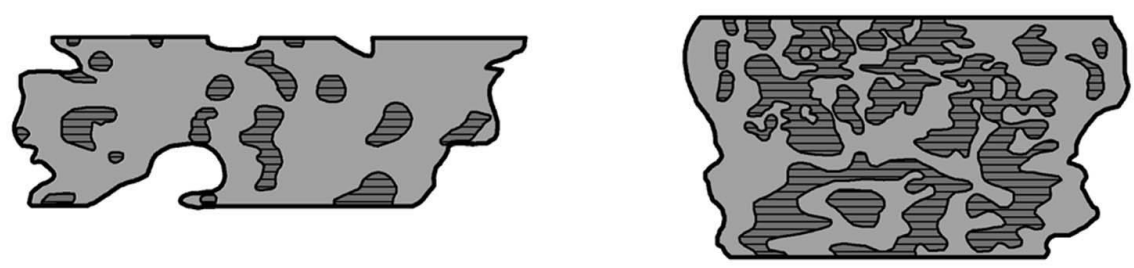

$1.0 \mu \mathrm{m}$

Fig. 9. Summary diagram of the changes observed for endbulbs of Held and spherical bushy cells (adapted from Ryugo et al., 1997). Compared to hearing cats, the deaf cats exhibit less complex and smaller endbulbs of Held, shrunken spherical bushy cells, loss of synaptic vesicles, and hypertrophy and flattening of PSDs. It is proposed that these structural alterations would impair processing involved in the analysis of binaural time differences.

ing approximately a $20 \%$ reduction. If we increase profile size by an equal amount, synaptic vesicle density in modified endbulbs is the same for both groups of cats.

\subsection{Extracellular space}

In normal hearing cats, glial processes form lamellar capsules around the synaptic interface between modified 
endbulbs and globular bushy cells. They also extend finger-like extensions into the extracellular spaces created by a separation of the pre- and postsynaptic membrane. In congenitally deaf cats, the glial encapsulation remains but there is a conspicuous loss of extracellular space. This loss seems due to a flattening of the presynaptic membrane against the globular bushy cell somata. It becomes of interest to address these spaces because of their normally reliable association to synaptic active zones and because their disappearance in congenitally deaf cats is so striking.

What might be the function of these intercellular channels and lacunae? One idea is related to transmitter inactivation. Glutamate is thought to be the main neurotransmitter for the cochlear nerve (Wenthold et al., 1993; Hackney et al., 1996). Transmitter released from auditory nerve endings must be rapidly removed from the synaptic cleft so that the postsynaptic cell is prepared for the next transmission. The removal and inactivation of neurotransmitter is accomplished by a highly efficient system of uptake and transporter molecules that surround glutamatergic synapses (Bergles et al., 1997, 1999; Diamond and Jahr, 1997). It is inviting to consider that plasma membrane lining these intercellular cisternae and invading astrocytic processes contain the relevant transporter molecules. With deafness, there is a cessation of activity in auditory nerve fibers (Ryugo et al., 1998). Does this situation eliminate the need for synaptic readiness and therefore result in the loss of extracellular space? Surface membrane of the modified endbulbs clearly must resorb given the volume loss, and one result would necessarily be a smoothing of the ending surface. A preference for transporter molecules to be distributed along the membranes lining these perisynaptic cisternae could provide important insights into synaptic function.

\subsection{Clinical implications}

The context for interpreting these alterations is established by observations that deaf individuals, provided with a cochlear implant as an adult, report difficulties in speech comprehension. Speech represents a complex stream of sounds, variable over time in frequency spectra, amplitude and prosody. The timing pattern of sounds comprises one major component of the speech signal. If deafness induces synaptic alterations throughout the central auditory nervous system, one can imagine that transmission would be one of the first processes to be affected. Any alteration in synaptic transmission would corrupt the temporal processing of speech. If all auditory synapses are equally affected, then processing would be delayed in time at progressively higher centers, and neural activity would not be closely linked to environmental sound cues. Perhaps a more devastating scenario would be one where different classes of auditory synapses are affected to different degrees. This situation would add variable and unpredictable delays to separate circuits, and the entire system would be desynchronized with respect to itself as well as to acoustic cues. The circuit involving endbulbs of Held and spherical bushy cells is implicated in the processing of interaural timing differences, an important cue for azimuthal localization of low frequency sounds (Yin and Chan, 1990; Fitzpatrick et al., 1997). The circuit involving modified endbulbs and globular bushy cells, however, is part of the processing of interaural intensity differences, a cue for azimuthal localization of high frequency sounds (Boudreau and Tsuchitani, 1968; Irvine, 1992). Conflicting information from these separate systems would impair the temporal processing of binaural sounds. The resulting disruption of sound localization would compromise the partitioning of acoustic input into distinct streams of sounds arising from different locations, and have a most serious effect on speech perception in the presence of background noise.

\section{Acknowledgements}

The authors thank Brian Rosenbaum and Hugh Cahill for technical assistance. This work was supported by NIH/NIDCD Grants DC00232 and DC00027, and a resident research grant from the American Academy of Otolaryngology-Head and Neck Surgery.

\section{References}

Bergles, D.E., Diamond, J.S., Jahr, C.E., 1999. Clearance of glutamate inside the synapse and beyond. Curr. Opin. Neurobiol. 9, 293-298.

Bergles, D.E., Dzubay, J.A., Jahr, C.E., 1997. Glutamate transporter currents in bergmann glial cells follow the time course of extrasynaptic glutamate. Proc. Natl. Acad. Sci. USA 94, 14821-14825.

Bergsma, D., Brown, K., 1971. White fur, blue eyes, and deafness in the domestic cat. J. Hered. 62, 171-185.

Blackburn, C.C., Sachs, M.B., 1989. Classification of unit types in the anteroventral cochlear nucleus: post-stimulus time histograms and regularity analysis. J. Neurophysiol. 62, 1303-1329.

Bosher, S., Hallpike, C., 1965. Observations on the histological features, development and pathogenesis of the inner ear degeneration of the deaf white cat. Proc. R. Soc. B 162, 147-170.

Boudreau, J.C., Tsuchitani, C., 1968. Binaural interaction in the cat superior olive S segment. J. Neurophysiol. 31, 442-454.

Brawer, J.R., Morest, D.K., Kane, E.C., 1974. The neuronal architecture of the cochlear nucleus of the cat. J. Comp. Neurol. 155, 251-300.

Brighton, P., Ramesar, R., Winship, I., 1991. Hearing impairment and pigmentary disturbance. Ann. N.Y. Acad. Sci. 630, 152-166.

Cant, N.B., Morest, D.K., 1978. Axons from non-cochlear sources in the anteroventral cochlear nucleus of the cat. A study with the rapid Golgi method. Neuroscience 3, 1003-1029.

Diamond, J.S., Jahr, C.E., 1997. Transporters buffer synaptically re- 
leased glutamate on a submillisecond time scale. J. Neurosci. 17, 4672-4687.

Deol, M.S., 1970. The relationship between abnormalities of pigmentation and of the inner ear. Proc. R. Soc. Lond. B 175, 201-217.

Doucet, J.R., Ryugo, D.K., 1997. Projections from the venteral cochlear nucleus to the dorsal cochlear nucleus in rats. J. Comp. Neurol. 385, 245-264.

Fekete, D.M., Rouiller, E.M., Liberman, M.C., Ryugo, D.K., 1984. The central projections of intracellularly labeled auditory nerve fibers in cats. J. Comp. Neurol. 229, 432-450.

Fitzpatrick, D.C., Batra, R., Stanford, T.R., Kuwada, S., 1997. A neuronal population codes for sound localization. Nature 388, 871-874.

Fryauf-Bertschy, H., Tyler, R.S., Kelsay, D.M., Gantz, B.J., 1992. Performance over time of congenitally deaf and postlingually deafened children using a multichannel cochlear implant. J. Speech Hear. Res. 35, 913-920.

Gantz, B., Tyler, R., Woodworth, G., Tye-Murray, N., Fryauf-Bertschy, H., 1994. Results of multichannel cochlear implants in congenital and acquired prelingual deafness in children: Five year follow up. Am. J. Otol. 15, 1-8.

Hackney, C.M., Osen, K.K., Kolston, J., 1990. Anatomy of the cochlear nuclear complex of guinea pig. Anat. Embryol. 182, 123 149.

Hackney, C.M., Osen, K.K., Ottersen, O.P., Storm-Mathisen, J., Manjaly, G., 1996. Immunocytochemical evidence that glutamate is a neurotransmitter in the cochlear nerve: A quantitative study in the guinea-pig anteroventral cochlear nucleus. Eur. J. Neurosci. 8, 79-91.

Harrison, J.M., Irving, R., 1966. The organization of posteroventral cochlear nucleus in the rat. J. Comp. Neurol. 126, 391-402.

Irvine, D.R.F., 1986. The Auditory Brainstem. A Review of the Structure and Function of Auditory Brainstem Processing Mechanisms. Springer-Verlag, New York.

Irvine, D.R.F., 1992. Physiology of the auditory brainstem. In: Popper, A.N. and Fay, R.R. (Eds.), The Mammalian Auditory Pathway: Neurophysiology. Springer-Verlag, New York, pp. 153231.

Klinke, R., Kral, A., Heid, S., Tillein, J., Hartmann, R., 1999. Recruitment of the auditory cortex in congenitally deaf cats by longterm cochlear electrostimulation. Science 285, 1729-1733.

Larsen, S.A., Kirchhoff, T.M., 1992. Anatomical evidence of plasticity in the cochlear nuclei of deaf white cats. Exp. Neurol. 115, 151157.

Lenn, N.J., Reese, T.S., 1966. The fine structure of nerve endings in the nucleus of the trapezoid body and the ventral cochlear nucleus. Am. J. Anat. 118, 375-390.

Lorente de Nó, R., 1981. The Primary Acoustic Nuclei. Raven Press, New York.

Mair, I.W., 1973. Hereditary deafness in the white cat. Acta Otolaryngol. 314, 1-48.

Mandelbrot, B.B., 1982. The Fractal Geometry of Nature. Freeman, New York.

Manis, P.B., Marx, S.O., 1991. Outward currents in isolated ventral cochlear nucleus neurons. J. Neurosci. 11, 2865-2880.

Moore, J.K., Niparko, J.K., Miller, M., Linthicum, F., 1994. Effect of profound deafness on a central auditory nucleus. Am. J. Otol. 15, $588-595$.

Nadol, J.B., Jr., Burgess, B., 1982. Cochleosaccular degeneration of the inner ear and progressive cataracts inherited as an autosomal dominant trait. Laryngoscope 92, 1028-1037.

Nusser, Z., Mulvihill, E., Streit, P., Somogyi, P., 1994. Subsynaptic segregation of metabotropic and ionotropic glutamate receptors as revealed by immunogold localization. Neuroscience 61, 421-427.

Oertel, D., 1991. The role of intrinsic neuronal properties in the en- coding of auditory information in the cochlear nuclei. Curr. Opin. Neurobiol. 1, 221-228.

Ostapoff, E.M., Morest, D.K., 1991. Synaptic organization of globular bushy cells in the ventral cochlear nucleus of the cat: a quantitative study. J. Comp. Neurol. 314, 598-613.

Pfeiffer, R.R., 1966. Classification of response patterns of spike discharges for units in the cochlear nucleus: tone burst stimulation. Exp. Brain Res. 1, 220-235.

Porter, R., Ghosh, S., Lange, G.D., Smith, T.G., Jr., 1991. A fractal analysis of pyramidal neurons in mammalian motor cortex. Neurosci. Lett. 130, 112-116.

Pujol, R., Rebillard, M., Rebillard, G., 1977. Primary neural disorders in the deaf white cat cochlea. Acta Otolaryngol. 83, 59-64.

Quittner, A.L., Steck, J.T., 1991. Predictors of cochlear implant use in children. Am. J. Otol. 12 (Suppl.), 89-94.

Rawitz, B., 1896. Gehörorgan und gehirn eines weissen hundes mit blauen augen. Morphol. Arb. 6, 545-554.

Rebillard, M., Rebillard, G., Pujol, R., 1981. Variability of the hereditary deafness in the white cat. I. Physiology. Hear. Res. 5, 179-181.

Rouiller, E.M., Cronin-Schreiber, R., Fekete, D.M., Ryugo, D.K., 1986. The central projections of intracellularly labeled auditory nerve fibers in cats: An analysis of terminal morphology. J. Comp. Neurol. 249, 261-278.

Rubio, M.E., Wenthold, J.R., 1997. Glutamate receptors are selectively targeted to postsynaptic sites in neurons. Neuron 18, 939950.

Ryugo, D.K., Pongstaporn, T., Huchton, D.M., Niparko, J.K., 1997. Ultrastructural analysis of primary endings in deaf white cats: Morphologic alterations in endbulbs of Held. J. Comp. Neurol. 385, 230-244.

Ryugo, D.K., Rosenbaum, B.T., Kim, P.J., Niparko, J.K., Saada, A.A., 1998. Single unit recordings in the auditory nerve of congenitally deaf white cats: morphological correlates in the cochlea and cochlear nucleus. J. Comp. Neurol. 397, 532-548.

Ryugo, D.K., Sento, S., 1991. Synaptic connections of the auditory nerve in cats: Relationship between endbulbs of Held and spherical bushy cells. J. Comp. Neurol. 305, 35-48.

Ryugo, D.K., Willard, F.H., Fekete, D.M., 1981. Differential afferent projections to the inferior colliculus from the cochlear nucleus in the albino mouse. Brain Res. 210, 342-349.

Saada, A.A., Niparko, J.K., Ryugo, D.K., 1996. Morphological changes in the cochlear nucleus of congenitally deaf white cats. Brain Res. 736, 315-328.

Scheibe, A., 1892. A case of deaf-mutism, with auditory atrophy and anomalies of development in the membranous labyrinth of both ears. Arch. Otolaryngol. 211, 12-22.

Schofield, B.R., Cant, N.B., 1996. Origins and targets of commissural connections between the cochlear nuclei in guinea pigs. J. Comp. Neurol. 375, 128-146.

Schwartz, I.R., Higa, J.F., 1982. Correlated studies of the ear and brainstem in the deaf white cat: Changes in the spiral ganglion and the medial superior olivary nucleus. Acta Otolaryngol. 93, 918.

Spangler, K.M., Cant, N.B., Henkel, C.K., Farley, G.R., Warr, W.B., 1987. Descending projections from the superior olivary complex to the cochlear nucleus of the cat. J. Comp. Neurol. 259, 452-465.

Spirou, G.A., Brownell, W.E., Zidanic, M., 1990. Recordings from cat trapezoid body and HRP labeling of globular bushy cell axons. J. Neurophysiol. 63, 1169-1190.

Suga, F., Hattler, K.W., 1970. Physiological and histopathological correlates of hereditary deafness in animals. Laryngoscope 80, 81-104.

Tolbert, L.P., Morest, D.K., 1982a. The neuronal architecture of the anteroventral cochlear nucleus of the cat in the region of the co- 
chlear nerve root: Golgi and Nissl methods. Neuroscience 7, 3013 3030.

Tolbert, L.P., Morest, D.K., 1982b. The neuronal architecture of the anteroventral cochlear nucleus of the cat in the region of the cochlear nerve root: Horseradish peroxidase labelling of identified cell types. Neuroscience 7, 3031-3052.

Tolbert, L.P., Morest, D.K., 1982c. The neuronal architecture of the anteroventral cochlear nucleus of the cat in the region of the cochlear nerve root: Electron microscopy. Neuroscience 7, 30533067.

Tyler, R.S., Summerfield, A.Q., 1996. Cochlear implantation: Relationships with research on auditory deprivation and acclimatization. Ear Hear. 17 (Suppl.), 38s-50s.

Waardenburg, P.J., 1951. A new syndrome combining developmental anomalies of the eyelids, eyebrows and nose root with pigmentary defects of the iris and head hair with congenital deafness. Am. J. Hum. Genet. 3, 195-253.

Waltzman, S., Fisher, S., Niparko, J.K., Cohen, N., 1994. Predictors of postoperative performance with cochlear implants. Ann. Otol. Rhinol. Laryngol. 104, 15-18.

Warr, W.B., 1982. Parallel ascending pathways from the cochlear nucleus: Neuroanatomical evidence of functional specialization. In: Neff, W.D. (Ed.), Contributions to Sensory Physiology. Academic Press, New York, pp. 1-38.
Wenthold, R.J., Hunter, C. and Petralia, R.S., 1993. Excitatory amino acid receptors in the rat cochlear nucleus. In: Merchan, M.A., Juiz, J.M., Godfrey, D.A. and Mugnaini, E. (Eds.), The Mammalian Cochlear Nuclei: Organization and Function. Plenum, New York, pp. 179-194.

West, C.D., Harrison, J., 1973. Transneuronal cell atrophy in the deaf white cat. J. Comp. Neurol. 151, 377-398.

Wolff, D., 1942. Three generations of deaf white cats. J. Hered. 33, $39-43$.

Yin, T.C.T. and Chan, J.C.K., 1988. Neural mechanisms underlying interaural time sensitivity to tones and noise. In: Edelman, G.M., Gall, W.E. and Cowan, W.M. (Eds.), Auditory Function. Wiley and Sons, Inc., New York, pp. 385-430.

Yin, T.C.T., Chan, J.C.K., 1990. Interaural time sensitivity in medial superior olive of cat. J. Neurophysiol. 64, 465-488.

Young, E.D., Shofner, W.P., White, J.A., Robert, J.-M. and Voigt, H.F., 1988. Response properties of cochlear nucleus neurons in relationship to physiological mechanisms. In: Edelman, G.M., Gall, W.E. and Cowan, W.M. (Eds.), Auditory Function: Neurobiological Bases of Hearing. John Wiley and Sons, New York, pp. 277-312. 